\title{
Strengthening Social and Behavior Change in Postabortion Care: A Call to Action for Health Professionals
}

\author{
Erin Mielke, ${ }^{a}$ Hope Hempstone, ${ }^{a}$ Ashlie Williams ${ }^{a}$
}

Social and behavior change approaches have shown promise for addressing the demand- and supply-side challenges in postabortion care. As implementers seek to improve the quality of postabortion care, systematically integrating long-standing models and emerging approaches, including behavioral economics, humancentered design, and attribute-based models of behavior change, can promote positive health outcomes.

\section{INTRODUCTION}

U nsafe abortion is the fifth leading direct cause of maternal deaths globally and in developing countries. ${ }^{1}$ Postabortion care (PAC) programs, encompassing both facility-based and community-based interventions, are essential to address complications of induced and spontaneous abortion, prevent subsequent unintended pregnancies, and ensure healthy timing and spacing of intended pregnancies. The 3 key components of PAC programs are (1) emergency treatment for complications of spontaneous or induced abortion, (2) family planning counseling and service provision, and (3) community engagement. ${ }^{2}$ However, access to and provision of high-quality PAC are compromised in many settings by pervasive social stigma around induced and spontaneous abortion, provider bias, and complex counseling requirements. These barriers impede timely care seeking for complications of abortion and limit access to the full range of voluntary family planning methods during PAC. Social and behavior change, which is widely recognized to be a key component of effective reproductive health programming, offers particular potential to improve the quality and impact of PAC. Social and behavior change approaches include outreach and community mobilization, counseling and interpersonal communication, behavioral "nudges," and use of digital platforms targeting clients or providers, among many others. Robust application of these approaches can motivate health-seeking behaviors before, during, and after the time a client enters a health facility for PAC and shape the care a client receives in a facility. Achieving positive outcomes among PAC clients depends on the extent to which programs (1) attend to the varied needs of

a Bureau for Global Health, U.S. Agency for International Development, Washington, DC, USA.

Correspondence to Erin Mielke (emielke@usaid.gov). different client groups and (2) support effective interaction of providers and clients in high-quality counseling and follow-up care. Both factors are key tenets of effective behavior change programming. PAC programs that successfully conduct client-centered demand creation, counseling, and follow-up and address the full range of barriers to delivery of high-quality and nonjudgmental care will be well equipped to overcome the common challenges in PAC programming discussed in this article.

\section{ADDRESSING COMMON PAC CHALLENGES THROUGH SOCIAL AND BEHAVIOR CHANGE}

Programmatic experience suggests that key behaviorrelated challenges in the delivery of high-quality PAC services arise before the PAC client reaches a facility, during her visit to a facility, and after she leaves a facility. These challenges include the following ${ }^{3}$ :

Before:

- Ensuring timely care seeking by women and their partners

During:

- Promoting respectful treatment of PAC clients by providers and addressing the stigma that specific client groups may experience in interactions with providers

- Ensuring that during counseling, providers address client needs for clear information about return to fertility and family planning options and acknowledge barriers to postabortion family planning

- Ensuring providers offer a full range of voluntary family planning methods prior to discharging the client, including long-acting reversible contraceptives and permanent methods 


Key challenges in
the delivery of
high-quality PAC
services arise
before, during,
and after a PAC
client's visit to a
facility.

After:

- Supporting clients in returning to services to facilitate both voluntary contraceptive continuation and follow-up for clients whose treatment requires return visits

While additional formal evaluation of social and behavior change in the context of PAC is needed, lessons learned from programmatic experience in this and other areas of reproductive health suggest that intentional use of behavior change principles and approaches is necessary to address common challenges in PAC programming.

\section{Before PAC Clients Reach a Facility}

Seeking care at the first sign of complication is essential to effective treatment of spontaneous and induced abortions. Facilitating timely care seeking requires attention to barriers to accessing services, which may be specific to a given context or client group. Lack of information about the warning signs of spontaneous abortion, dangerous complications of spontaneous and induced abortion, and where to seek PAC prevents women from seeking help. ${ }^{4,5}$ In many settings, fear of abuse, ill treatment, or legal reprisal arising from the stigma associated with abortion also deters women from seeking medical care. ${ }^{5}$ Youth face particular barriers to timely care seeking, including lack of trust in providers, concerns about confidentiality, and fear of being stigmatized for engaging in risky behaviors. ${ }^{6,7}$

PAC programs have successfully intervened at the community level to address barriers to care seeking and reinforce supportive norms. In Kenya and Somalia, community education, training of community health workers and community preparedness have effectively increased awareness, acceptance, and utilization of PAC, including voluntary use of postabortion family planning. ${ }^{8-10}$ Organizations in Bolivia and Kenya successfully applied the community action cycle to learn about the concerns of distinct segments of the local population (e.g., women, men, and adolescents). In turn, community members learned about PAC services, participated in ensuring service delivery, and demonstrated ownership of programs to improve access to and use of PAC. ${ }^{11-13}$ In Kenya, this approach reduced stigma among family and community members and improved their care-seeking responses to bleeding during pregnancy. ${ }^{11}$

PAC programs must consistently apply proven practices in behavioral design, including systematic diagnosis of barriers to service utilization among key client groups. In addition to addressing the common barriers cited above, implementers should employ formative research approaches used in behavioral programming as a means to generate insights about client perceptions and motivations. In particular, immersive and participatory approaches grounded in human-centered design show promise as a means to better understand and address barriers to care seeking. Human-centered design is an iterative process that includes developing a deep understanding of the people affected by a problem, identifying opportunities for design to address that problem, prototyping potential solutions, and repeatedly testing and refining those prototypes. ${ }^{14}$ The end-user is directly engaged throughout each stage of this process. In Côte d'Ivoire, for example, a human-centered design project employed group interviews, field observations, and participatory brainstorming and prototyping workshops with stakeholders to understand barriers to family planning use among young men working in the informal sector and their partners. ${ }^{15}$ A deep understanding of barriers can inform both the development of social and behavior change messages and the selection of communication channels or approaches. ${ }^{16}$ Postabortion care seeking may also be improved by promoting utilization of reproductive health services as an entire category through proven approaches such as branding of services, mass media campaigns, community activation events, or targeted interpersonal communication. With regard to facilitating youth access to reproductive health services, multiple studies show that promotion of reproductive health care via school and community outreach and mass media improves care seeking among young people and positively influences parental and other gatekeepers' approval of reproductive health services for youth. ${ }^{17-19}$ This improvement is attained by increasing awareness of services and trust in providers and the health system as an entity before emergency care is required.

\section{During a PAC Client's Visit to a Health Facility}

The client-provider interaction during health care provision represents a critical opportunity to build trust and establish healthy behaviors pertaining to family planning and reproductive health care seeking. Four distinct but interrelated challenges may influence the quality of care offered during a PAC client's visit to a health facility. Failing to prevent these challenges can ultimately hinder 
adoption of voluntary family planning methods that enable women and their partners to achieve their desired fertility. First, providers may treat clients with disrespect or restrict care due to norms or attitudes associated with abortion, sexuality, and sexual health among specific client groups; circumstances such as a subsequent abortion or failure to use family planning; and/or use of family planning after pregnancy loss. ${ }^{7,20-22}$ Second, providers may not adequately explain healthy spacing of pregnancy. The World Health Organization recommends women delay pregnancy for at least 6 months after an abortion $^{23}$ (although a recent meta-analysis in mainly developed countries showed a shorter interval following miscarriage is not associated with adverse outcomes ${ }^{24}$ ). Similarly, providers may not adequately explain return to fertility, which can occur within 2 weeks after a first trimester spontaneous or induced abortion. ${ }^{23}$ One cross-sectional study in Egypt showed that twothirds of 412 women who received PAC did not know when fertility returns after abortion and were not intending to use contraception, despite three-quarters wanting to postpone childbearing. ${ }^{25}$ Women in Russia who left the health facility without a clear understanding of their return to fertility following abortion were 4 times more likely to have a repeat abortion than those with accurate knowledge. ${ }^{26}$ Finally, providers may fail to counsel PAC clients on the full range of family planning methods available to them and fail to offer these methods prior to discharging the client. ${ }^{26,27}$ Incomplete counseling and failure to offer voluntary family planning may be influenced in part by assumptions about client preferences, provider bias toward certain family planning methods (which providers perceive to be safer following an abortion or more appropriate for certain client groups), or low motivation among providers and lack of performance feedback. ${ }^{28-29}$

To prevent these challenges, PAC programming has successfully employed a range of approaches to influence provider behaviors pertaining to counseling PAC clients, particularly about postabortion family planning. Many PAC programs have integrated discussions of provider attitudes and values into trainings that seek to reduce stigma toward women and adolescents who need reproductive health services, dispel misconceptions about contraceptive methods, and build effective counseling skills. These discussions offer opportunities for providers to reflect on how their own values and beliefs influence their interactions with clients. $^{30,31}$ Adaptable training materials to build empathy with different types of clients and distinguish between personal beliefs and professional responsibilities are available. ${ }^{32}$ Similarly, attention to expanding the contraceptive method mix offered to PAC clients has increased voluntary uptake of highly effective methods. Programs in Ethiopia and Guinea enhanced access to longacting reversible contraceptives for PAC clients and noted that a broader method mix can satisfy clients with a variety of needs. ${ }^{33,34}$ To support sustained improved practice, some Latin American PAC programs incorporated complementary provider behavior change approaches, such as the use of peer opinion leaders to promote best practices and strategic placement of visual reminders of clinical guidelines. ${ }^{35}$ Across 10 countries in Asia and sub-Saharan Africa, provider behavior change was reinforced by post-learning follow-up by mentors to reinforce new skills, provide performance feedback, and resolve obstacles to care. ${ }^{32}$ Provider job aids that improve motivation and enable facilities to track performance improvements have proved effective in Ethiopia. ${ }^{36,37}$ Finally, recent years have seen growing use of behavioral economics (i.e., applying psychological insights such as non-conscious biases and mental models that influence decision making) to promote provider behavior change. In Nepal, for example, one intervention made effective use of peer comparison approaches to allow providers to compare their health center's performance to other similar centers, increasing providers' motivation to improve quality of counseling and increasing voluntary family planning uptake during PAC. ${ }^{29}$

PAC programs can build on the rapidly growing evidence base for provider behavior change as a means to improve not only the knowledge and skills that underpin effective counseling, but the full range of motivational and normative influences affecting providers. To do so, implementers must use formative research to analyze specific drivers of provider behavior. As with programs targeting PAC clients themselves, the insights derived from this research can inform segmentation $^{38}$ and profiling of providers and identify important behavioral determinants, thus better targeting interventions to change provider behavior. Provider behavior change approaches must also clearly define specific, measurable behaviors and practices that constitute quality PAC counseling and respectful care, such as engagement with clients as active participants in a 2-way counseling dialogue. Adherence to these and other proven practices in behavioral design offer potential to
PAC programming has successfully employed several approaches to influence provider behaviors in counseling PAC clients. 


Behavioral design
may deepen the
impact of
traditional
knowledge- and
skills-based
interventions to
improve client-
provider
interaction.

deepen the impacts of more traditional knowledge- and skills-based interventions for improving client-provider interaction.

PAC programs can further improve the quality of client-provider interaction through continued attention to the drivers of client behavior, specificity in behavior change messaging, and promotion of client engagement during care and counseling. Counseling and other communication approaches should acknowledge and address barriers to postabortion family planning, including social norms regarding fertility and couples' communication. ${ }^{39}$ Activities that improve the quality of counseling can affect not only uptake of family planning but also its continuation. ${ }^{40}$ In Northeast Brazil, for example, female PAC clients who received counseling personalized to their plans for future contraceptive use and their beliefs and previous experiences were $41 \%$ more likely to be using a contraceptive method 6 months after an abortion than those who received only standardized information. ${ }^{41}$ In addition, activities that directly empower clients to pose questions and express their reproductive intentions can prompt providers to offer further information and address clients' concerns, as demonstrated by a community education and mass media program in Indonesia. ${ }^{42}$ Such approaches may be particularly relevant for young PAC clients who wish to delay or space childbearing but are not using contraception.

\section{After a PAC Client Leaves a Facility}

PAC programming must address challenges relating to support for voluntary contraceptive initiation or continuation and care for clients who require follow-up treatment. Clients who receive counseling and choose a voluntary family planning method may require assistance with accessing ongoing supplies of short-acting methods ${ }^{43}$ or follow-up to obtain long-acting or permanent methods when it is not possible to obtain these during the initial visit or referral to a different facility is required. ${ }^{5}$ Women who choose an intrauterine device or tubal ligation following treatment with misoprostol, for example, require a follow-up visit to ensure that evacuation of the uterus is complete and no complications are present, such as prolonged heavy bleeding or fever. ${ }^{5}$

Social and behavior change interventions within PAC programs enhance a client's followup care, including family planning, and reinforce linkages between the client's home and health care workers. Client communication materials facilitate follow-up care. Several international professional associations and development partners recommend that PAC clients should receive simple written instructions for the use of their method, along with concise information about common side effects and benefits. ${ }^{44}$ In Sri Lanka, women who received an informational leaflet during antenatal care were significantly more likely to accept an intrauterine device following delivery. ${ }^{45}$ Providing takehome information during PAC may similarly support self-care and adoption or continuation of family planning after treatment for complications of a spontaneous or induced abortion. Examples of such client communication materials and provider training materials can be found online and may be adapted to the needs of specific audiences or cultural contexts as needed. ${ }^{46,47}$

Mobile phone-based communication has shown promise to facilitate access to health information and services in low-resource settings. A randomized control trial in Cambodia found that follow-up communication through mobile phones supports postabortion contraceptive use. It helped women retain family planning information provided during PAC and prompted women who wanted a long-acting method but did not receive one during the initial PAC visit to return for an implant or intrauterine device. ${ }^{48}$ This channel of communication was as effective as home visits in sustaining use of long-acting methods at 12month follow-up post insertion in rural Punjab, Pakistan. ${ }^{49}$ Mobile phones are an effective tool for facilitating access to care and information and promoting behavior change among youth. ${ }^{50} \mathrm{PAC}$ programs considering mobile phone-based communication must give careful attention to risks to confidentiality, such as shared use of a mobile phone among family members.

Evidence suggests that engaging the male partners of PAC clients in counseling, when acceptable to clients themselves, can improve health outcomes. PAC programs in Bolivia and Tanzania found that engaging partners by informing them of the client's condition and providing both with family planning counseling helped to ensure safe recovery and increased voluntary family planning continuation. ${ }^{51,52}$ In China and Egypt, counseling partners on follow-up care, postabortion warning signs, sources of referral care, return to fertility, and family planning also increased family planning usage and physical, material, and emotional support for the clients during recovery. ${ }^{53,54}$

In general, promotion of voluntary contraceptive continuation or return to services remains less understood than either creation of initial demand for services or improvement of client-provider interaction. 
Improved design and measurement of activities addressing behavioral initiation or maintenance after a client leaves a facility is an area of increasing collaboration between social and behavior change and service delivery professionals. The concerns of PAC program implementers constitute an important component of this discourse. The rapidly evolving thinking in this area affords PAC program implementers an opportunity to build upon emerging practices and develop innovative solutions to the challenges they face. For example, a growing body of gray literature pertaining to understanding and grouping similar behaviors and the attributes of those behaviors ${ }^{55,56}$ may allow for application of lessons learned from the promotion of other private, stigmatized, or provider-dependent behaviors. Interventions informed by behavioral economics to facilitate health seeking after PAC merit exploration given the amount of information associated with postabortion recovery, return to fertility, and adoption or continuation of family planning and with the normative and emotional context in which clients consider this information. Finally, reproductive "selfcare" and direct-to-consumer family planning methods (i.e., not requiring a health worker to administer, such as condoms, oral contraceptives, or mobile phone applications to track fertile days once a woman's regular menstrual cycle resumes), which are increasingly facilitated by mobile technology, may be particularly relevant in the context of PAC programming.

\section{CONCLUSION}

PAC programs have successfully used communitybased social and behavior change approaches and provider behavior change interventions to support clients in accessing postabortion services and adopting voluntary family planning. To ensure that all women have access to high-quality PAC, implementers must build upon this important foundation through continued application of proven practices in behavior change, including formative research, audience segmentation, and the use of iterative, multichannel communication approaches that target clients, providers, and community members. Concomitantly, implementers should seize the opportunity to play a leading role in the application of social and behavior change approaches for PAC by leveraging new trends in behavioral economics, human-centered design, and attribute-based models of behavior change and increasing alignment between demand-side and supply-side programming.
Acknowledgments: We thank all the reviewers whose insights and feedback helped to strengthen this call to action.

Funding: This work received no specific grant from any funding agency in the public, commercial, or not-for-profit sectors.

Disclaimer: The contents are the responsibility of the authors and do not necessarily reflect the views of the United States Agency for International Development or the U.S. Government.

Competing Interests: None declared.

We should

build our understanding of how to address behavioral initiation or maintenance after a client leaves a facility.

\section{REFERENCES}

1. Say L, Chou D, Gemmill A, et al. Global causes of maternal death: a WHO systematic analysis. Lancet Glob Health. 2014;2(6): e323-e333. CrossRef. Medline

2. High Impact Practices in Family Planning (HIPs). Postabortion family planning: strengthening the family planning component of postabortion care. Washington, DC: HIPs; 2012. https://fphighim pactpractices.org/briefs/postabortion-family-planning/. Accessed March 12, 2019.

3. Curtis C, Huber D, Moss-Knight T. Postabortion family planning: addressing the cycle of repeat unintended pregnancy and abortion. Int Perspect Sex Reprod Health. 2010;36(1):044-048. CrossRef. Medline

4. Banerjee SK, Andersen KL, Warvadekar J. Pathways and consequences of unsafe abortion: a comparison among women with complications after induced and spontaneous abortions in Madhya Pradesh, India. Int J Gynaecol Obstet. 2012;1 18(suppl 2): S1 13-S120. CrossRef. Medline

5. World Health Organization (WHO). Safe Abortion: Technical and Policy Guidance for Health Systems. 2nd ed. Geneva: WHO; 2012. https://www.who.int/reproductivehealth/publications/unsafe_ abortion/9789241548434/en/. Accessed April 4, 2019.

6. Mmari K, Marshall B, Hsu T, Shon JW, Eguavoen A. A mixed methods study to examine the influence of the neighborhood social context on adolescent health service utilization. BMC Health Serv Res. 2016;16(1):433. CrossRef. Medline

7. Population Services International. Nigeria: emerging insights for design. https://www.psi.org/wp-content/uploads/2017/03/ A360-Nigeria-Emerging-Insights-Deck.pdf. December 20, 2016. Accessed March 12, 2019.

8. Magak K, Mukenge M. Community-based abortion care midterm evaluation, Western Kenya. Pacific Institute for Women's Health; 2003.

9. Undie C, Birungi $\mathrm{H}$, Obare F, et al. Expanding access to comprehensive reproductive health and HIV information and services for married adolescent girls in Nyanza Province. Nairobi, Kenya: Population Council; 2012.

10. Chukwumalu K, Gallagher MC, Baunach S, Cannon A. Uptake of postabortion care services and acceptance of postabortion contraception in Puntland, Somalia. Reprod Health Matters. 2017. 25(51):48-57. CrossRef. Medline

11. Wickstrom J, Russell N, Escandon I. Engaging communities as partners in postabortion care: a desk review of the Community Postabortion Care Project in Nakuru, Kenya. New York: ACQUIRE Project/EngenderHealth; 2008. http://www.acquireproject.org/ archive/files/11.0_research_studies/er_study_11.pdf. Accessed March 12, 2019.

12. Ottolenghi $E$, Riveros $P$, Blanding S. Assessment of the Bolivia Postabortion Care Community Mobilization Program. New York: ACQUIRE Project/EngenderHealth; 2008. http://www.engender health.org/files/pubs/acquire-digital-archive/5.0_community engagement_marketing_and_communications/5.2_resources/ 
5.2.2 studies/cpac report revised final.pdf. Accessed March 12, 2019.

13. Undie C, Obare F, RamaRao S. Replication of the Community Mobilization for Postabortion Care (COMMPAC) model in Naivasha District, Rift Valley Province, Kenya: evaluation report. New York: EngenderHealth; 2012. http://www. respond-project.org/pages/ files/6_pubs/research-reports/Study9-COMMPAC-FinalEvaluation-December2012-Final-forweb.pdf. Accessed March 12, 2019.

14. What is human-centered design? Design Kit website. http://www. designkit.org/human-centered-design. Accessed March 12, 2019.

15. Emmanuel E, Antoine K, Amadou S, Fofana N. Implication des jeunes hommes du secteur informel dans la PF en utilisant un design centré sur l'homme en Côte d'lvoire [Engaging young men from the informal sector in FP using human-centered design in Cote d'Ivoire] Abidjan: Transform Phare; 2017. https://www. thecompassforsbc. org/sites/default/files/project_examples/Analyse\%20des\% 20barrieres\%20et\%20deviance\%20positif_FR.compressed.pdf. Accessed March 12, 2019.

16. Johns Hopkins Center for Communication Programs (CCP). Service Communication Implementation Kit. Baltimore, MD: CCP; 2017. https://sbccimplementationkits.org/service-communication/. Accessed March 12, 2019.

17. Ogu R, Maduka O, Alamina F, et al. Mainstreaming youth-friendly health services into existing primary health care facilities: experiences from South-South Nigeria. Int J Adolesc Med Health. January 25, 2018. Epub ahead of print. CrossRef. Medline

18. Denno DM, Hoopes AJ, Chandra-Mouli V. Effective strategies to provide adolescent sexual and reproductive health services and to increase demand and community support. J Adolesc Health. 2015;56(1 suppl):S22-S41. CrossRef. Medline

19. Gottschalk LB, Ortayli N. Interventions to improve adolescents' contraceptive behaviors in low- and middle-income countries: a review of the evidence base. Contraception. 2014;90(3):211-225. CrossRef. Medline

20. Sheppard N, Fiander A, Glasier A, Simpson E, Regan L. Attitudes of healthcare providers towards the provision of comprehensive abortion care (CAC) services in Western Cape, South Africa: the RCOG Leading Safe Choices (LSC) programme [abstract EP6.042]. BJOG. 2016;123(S2):121-129. CrossRef

21. Nielsen KK, Lusiola G, Kanama J, Bantamby J, Kikumbih N, Rasch V. Expanding comprehensive postabortion care to primary health facilities in Geita District, Tanzania. Afr J Reprod Health. 2009; 13(2):129-138. Medline

22. Cobb L, Putney P, Rochat R, et al. Global evaluation of USAID's postabortion care program. Washington, DC: Population Technical Assistance Project (POPTECH); 2001. http://pdf.usaid.gov/pdf_ docs/PNACN773.pdf. Accessed March 12, 2019.

23. World Health Organization Department of Reproductive Health and Research (WHO/RHR); Johns Hopkins Bloomberg School of Public Health/Center for Communications Programs (CCP), Knowledge for Health Project. Family Planning: A Global Handbook for Providers. 2018 ed. Baltimore, MD, and Geneva, Switzerland: CCP and WHO; 2018. http://www.fphandbook.org/. Accessed April 4, 2019.

24. Kangatharan C, Labram S, Bhattacharya S. Interpregnancy interval following miscarriage and adverse pregnancy outcomes: systematic review and meta-analysis. Hum Reprod Update. 2017;23(2):221231. CrossRef

25. Mahmoud G, Byomy S. Fertility awareness and family planning use among post abortion women in Egypt. Life Sci J. 2013;10(1):143150. http://www.lifesciencesite.com/lsj/life1001/021_13256 life1001_143_150.pdf. Accessed April 4, 2019.

26. David PH, Reichenbach L, Savelieva I, Vartapetova N, Potemkina R. Women's reproductive health needs in Russia: what can we learn from an intervention to improve post-abortion care? Health Policy Plan. 2007;22(2):83-94. CrossRef. Medline

27. Youssef $\mathrm{H}$, Adbel-Tawab N, Bratt J. Linking family planning with postabortion services in Egypt: testing the feasibility, acceptability and effectiveness of the two models of integration. New York: FRONTIERS in Reproductive Health, Population Council; 2007. http://pdf.usaid.gov/pdf_docs/PNADK094.pdf. Accessed March $12,2019$.

28. McDougall J, Fetters T, Clark KA, Rathavy T. Determinants of contraceptive acceptance among Cambodian abortion patients. Stud Fam Plann. 2009;40(2):123-132. CrossRef. Medline

29. Spring H, Datta S, Sapkota S. Using behavioral science to design a peer comparison intervention for postabortion family planning in Nepal. Front Public Health. 2016;4:123. CrossRef. Medline

30. McCarraher DR, Chen-Mok M, Oronoz AS, et al. Meeting the needs of adolescent post-abortion care patients in the Dominican Republic. J Biosoc Sci. 2010;42(4):493-509. CrossRef. Medline

31. Benson J, Andersen K, Healy J, Brahmi D. What factors contribute to postabortion contraceptive uptake by young women? A program evaluation in 10 countries in Asia and sub-Saharan Africa. Glob Health Sci Pract. 2017;5(4):644-657. CrossRef. Medline

32. Ganges F, Curtis C. Postabortion Care Curriculum: Trainer's Guide. Baltimore, MD: Jhpiego; 2010. https://www. postabortioncare.org/ sites/pac/files/PAC_TrainerGuide.pdf. Accessed March 12, 2019.

33. Pfitzer A, Hyjazi $Y$, Arnold $B$, et al. Inclusion of long-acting reversible contraceptives as an option for postabortion care clients in Guinea: results of an observational study. Glob Health Sci Pract. 2019; 7(suppl 2). CrossRef

34. Samuel M, Fetters T, Desta D. Strengthening postabortion family planning services in Ethiopia: expanding contraceptive choice and improving access to long-acting reversible contraception. Glob Health Sci Pract. 2016;4(suppl 2):S60-S72. CrossRef. Medline

35. Althabe F, Buekens P, Bergel E, et al; Guidelines Trial Group. A behavioral intervention to improve obstetrical care. N Engl J Med. 2008;358(18):1929-1940. CrossRef. Medline

36. Alemayehu T, Otsea K. GebreMikael A, Dagnew S, Healy J, Benson J. Abortion care improvements in Tigray, Ethiopia: using the Safe Abortion Care (SAC) approach to monitor the availability, utilization and quality of services. final report of a two-year project in 50 public sector facilities. Chapel Hill, NC: Ipas; 2009.

37. Wallace RR, Goodman S, Freedman LR, Dalton VK, Harris LH. Counseling women with early pregnancy failure: utilizing evidence, presenving preference. Patient Educ Couns. 2010;81(3):454-461. CrossRef. Medline

38. How to do audience segmentation. The Compass website. https:// www.thehealthcompass.org/how-to-guides/how-do-audiencesegmentation. Published 2014. Accessed March 12, 2019.

39. Evens E, Otieno-Masaba R, Eichleay M, et al. Post-abortion care services for youth and adult clients in Kenya: a comparison of services, client satisfaction and provider attitudes. J Biosoc Sci. 2014; 46(1):1-15. Medline

40. RamaRao S, Lacuesta M, Costello M, Pangolibay B, Jones $H$. The link between quality of care and contraceptive use. Int Fam Plan Perspect. 2003;29(2):76-83. CrossRef. Medline

41. Carneiro Gomes Ferreira AL, Impieri Souza A, Evangelista Pessoa R, Braga $C$. The effectiveness of contraceptive counseling for women in the postabortion period: an intervention study. Contraception. $2011 ; 84(4): 377-383$. CrossRef. Medline

42. Kim YM, Bazant E, Storey JD. Smart patient, smart community improving client participation in family planning consultations through a community education and mass-media program in Indonesia. Int Q Community Health Educ. 2006-2007;26(3):247270. CrossRef. Medline 
43. Darroch J, Sedgh G, Ball H. Contraceptive Technologies: Responding to Women's Needs. New York: Guttmacher Institute; 2011. https:// www.guttmacher.org/sites/default/files/report_pdf/contraceptivetechnologies.pdf. Accessed March 12, 2019.

44. Post abortion family planning: a key component of post abortion care. Consensus statement. International Federation of Gynecology and Obstetrics (FIGO) website. https://www.figo.org/sites/default/ files/uploads/project-publications/PAC-FP-Joint-StatementNovember2013-final_printquality.pdf. Published November 1 2013. Accessed March 12, 2019.

45. Karra M, Canning D, Foster S, et al. Location and content of counselling and acceptance of postpartum IUD in Sri Lanka. Reprod Health. 2017;14(1):42. CrossRef. Medline

46. When a pregnancy ends, you need to take care of yourself [brochure]. Postabortion Care website. http://wnw. postabortion care.org/sites/pac/files/Client_Brochure.pdf. Accessed March 12, 2019

47. World Health Organization (WHO). Counselling for Maternal and Newborn Health Care: A Handbook for Building Skills. Geneva: WHO; 2013. https://www.ncbi.nlm.nih.gov/books/NBK304195/. Accessed March 12, 2019.

48. Smith C, Ngo TD, Gold J, et al. Effect of a mobile phone-based intervention on post-abortion contraception: a randomized controlled trial in Cambodia. Bull World Health Organ. 2015;93(12):842850A. CrossRef. Medline

49. Hameed W, Azmat SK, Ali M, et al. Comparing effectiveness of active and passive client follow-up approaches in sustaining the continued use of long acting reversible contraceptives (LARC) in Rural Punjab: a multicentre, non-inferiority trial. PLoS One. 2016;1 1(9): e0160683. CrossRef. Medline

50. Ippoliti NB, L'Engle K. Meet us on the phone: mobile phone programs for adolescent sexual and reproductive health in low-to-middle income countries. Reprod Health. 2017;14(1):1 1. CrossRef. Medline
51. Billings $D$, Del Pozo $E$, Arévalo $H$. Testing a model for the delivery of emergency obstetric care and family planning services in the Bolivian public health system. Washington, DC: Ipas; 2003. https://mww. researchgate.net/publication/237333680_Testing_a_Model_for_the_ Delivery_of_Emergency_Obstetric_Care_and_Family_Planning Services_in_the_Bolivian_Public_Health_System. Accessed April 4, 2019.

52. Rasch V, Yambesi F, Kipingili R. Scaling up postabortion contraceptive service-results from a study conducted among women having unwanted pregnancies in urban and rural Tanzania. Contraception. 2005;72(5):377-382. CrossRef. Medline

53. Zhu JL, Zhang WH, Cheng Y, et al. Impact of post-abortion family planning services on contraceptive use and abortion rate among young women in China: a cluster randomised trial. Eur $J$ Contracept Reprod Health Care. 2009;14(1):46-54. CrossRef. Medline

54. Abdel-Tawab ND, Huntington D, Osman Hassan E, Youssef $H$, Nawar L. Recovery from abortion and miscarriage in Egypt: does counseling husbands help? In: Haberland N, Measham D, eds. Responding to Cairo: Case Studies of Changing Practice in Reproductive Health and Family Planning. New York: Population Council; 2002: 186-204.

55. Fogg BJ, Hreha J, Krieglstein R, Chanasyk K, Krishna G. Purple Path Behavior Guide. Stanford Persuasive Tech Lab; 2010. http:// captology.stanford.edu/wp-content/uploads/2010/12/PurplePath-Behavior-Guide.pdf. Accessed March 12, 2019.

56. Rimal RN, Turner M, Lapinski MK, Smith KS. The attribute-centered approach for understanding health behaviors: initial ideas and future research directions. Stud Commun Sci. 2011;1 1(1):15-34. https://www.researchgate.net/publication/303153757_The _ attribute-centered_approach_for_understanding_health_behaviors Initial_ideas_and_future_research_directions. Accessed April 4, 2019.

\section{Peer Reviewed}

Received: August 14, 2018; Accepted: March 15, 2019

Cite this article as: Mielke $\mathrm{E}$, Hempstone $\mathrm{H}$, Williams A. Strengthening social and behavior change in postabortion care: a call to action for health professionals. Glob Health Sci Pract. 2019;7(suppl 2):S215-S221. https://doi.org/10.9745/GHSP-D-18-00307

(c) Mielke et al. This is an open-access article distributed under the terms of the Creative Commons Attribution 4.0 International License (CC BY 4.0), which permits unrestricted use, distribution, and reproduction in any medium, provided the original author and source are properly cited. To view a copy of the license, visit http://creativecommons.org/licenses/by/4.0/. When linking to this article, please use the following permanent link: https:// doi.org/10.9745/GHSP-D-18-00307 